\title{
Temperature and surgical wound heat loss during orthopedic surgery: computer simulations and measurements
}

\author{
Natascha M. W. Severens, PhD • Wouter D. van Marken Lichtenbelt, PhD • \\ Arjan J. H. Frijns, PhD • Andre van Ooij, MD, PhD • Marco A. E. Marcus, PhD • \\ Bas A. J. M. de Mol, PhD • Anton A. van Steenhoven, PhD
}

Received: 10 April 2009/Accepted: 16 December 2009/Published online: 5 January 2010

(C) The Author(s) 2010. This article is published with open access at Springerlink.com

\section{To the Editor:}

During surgery under general anesthesia, thermal imbalances within the patient's body are common. These imbalances are caused by a variety of factors, including exposure to a cold operating environment and heat loss from surgical incisions. Perhaps the most important thermal imbalance is hypothermia, resulting initially from redistribution of body heat from the core to the periphery caused by impaired thermoregulatory responses due to anesthetics. There is lack of clarity regarding the contribution made by heat loss from the exposed wound to the total heat balance in humans because of technical difficulties. $^{1,2}$ The study by Lamke et al. elaborates on human wound heat loss. ${ }^{3}$ They assessed the evaporative water loss from wounds and exteriorized bowels by recording the rate of increase of vapour concentration in a closed measuring chamber placed over the exposed abdominal cavity. Information on wound temperature and wound heat loss are important because low wound temperatures are associated with a higher risk for wound infections and disturbed coagulation function, while evaporative heat losses may lead to hypovolemia.

N. M. W. Severens, PhD ( $\square)$ - A. J. H. Frijns, PhD .

A. A. van Steenhoven, $\mathrm{PhD}$

Technical University Eindhoven, Eindhoven, The Netherlands

e-mail: n.m.w.severens@tue.nl

N. M. W. Severens, PhD - B. A. J. M. de Mol, PhD

Academic Medical Center, Amsterdam, The Netherlands

W. D. van Marken Lichtenbelt, $\mathrm{PhD}$ - A. van Ooij, $\mathrm{MD}, \mathrm{PhD}$.

M. A. E. Marcus, $\mathrm{PhD}$

Maastricht University, Maastricht, The Netherlands

A. van Ooij, $\mathrm{MD}, \mathrm{PhD}$

VieCuri hospital, Venlo, The Netherlands
We recently developed a thermophysiological computer model, ThermoSEM (Eindhoven University of Technology and Maastricht University, Eindhoven and Masstricht, The Netherlands), that can be used to predict temperature responses and surgical wound heat of patients during surgery. ${ }^{4, \mathrm{~A}}$ The passive heat transfer processes in the body and between the body and the environment were modelled using fundamental heat transfer knowledge. A thermoregulatory model was formulated that describes the vasoconstriction response during surgery under general anesthesia and accounts for the decrease in metabolic rate during anesthesia. The model also contains flexible submodels that account for other thermal influences during surgery, e.g., surgical wound heat loss, use of heating mattresses and forced-air warmers, and ambient temperature. When running the model, all internal heat fluxes in the body are calculated as well as heat interactions between the body and the environment, leading to a transient whole body temperature prediction.

In this study, this thermophysiological model was used to simulate three orthopedic surgeries and to compare the model's output (temperature data of core, skin, and wound) to the data of three actual surgeries. Also, with help of the model, we intended to evaluate heat flows, including wound heat loss during orthopedic back surgery.

Three patients were followed during orthopedic back surgery. The study protocol was approved by the Maastricht University Medical Ethical Committee, and all patients signed an informed consent. The weight and height of the patients were noted, and measurements of the patients' skinfolds were taken prior to surgery to determine their body

\footnotetext{
$\overline{\text { A Severens }} N$. Modelling hypothermia in patients undergoing surgery. PhD thesis. Technische Universiteit Eindhoven, Eindhoven 2008.
} 
fat percentages. Skin temperatures were collected using wireless temperature sensors (maximum error $0.4^{\circ} \mathrm{C}$ ), and an ambulant infrared camera was used to map the surgical wound temperatures (accuracy $0.3^{\circ} \mathrm{C}$ ).

For running the simulations, the following information was entered into the model: patient characteristics (height, weight, body fat percentage, and body shape); ambient temperature; use of forced-air heaters; insulation of blankets/socks/mattress; and start times of surgery, incision, and closure. For the general model characteristics, refer to the references. ${ }^{4, \mathrm{~A}}$ Some assumptions were made for this particular type of surgery:

- The lengths of the abdomen segment and the actual incision were equal.

- Heat losses in circumferential directions were neglected.

- The air speed in the room was $0.05 \mathrm{~m} \cdot \mathrm{sec}^{-1}$.

- The administration of warmed fluids and the secretion of urine were in balance.

- The posterior abdomen segment was opened/closed stepwise from 0 to $75^{\circ}$ in five minutes, representing the incision.

- The volumetric perfusion value of the wound was 2.25 $\mathrm{L} \cdot \mathrm{m}^{-3} \cdot \mathrm{sec}^{-1}$.

- The blood layer was $0.5 \mathrm{~mm}$ thick and could evaporate. The blood properties were equal to water.

- The temperature of the surgery light was $50^{\circ} \mathrm{C}$ (measured with the infrared camera).

Results from the comparison of the model with the actual measurements: The core temperature bias of measurements and simulations was $-0.28 \pm 0.75^{\circ} \mathrm{C}$. Skin temperature bias was $-0.11 \pm 0.58^{\circ} \mathrm{C}$. Wound temperature bias was $-1.87 \pm 1.53^{\circ} \mathrm{C}$ (model prediction $28.3 \pm$ $0.8^{\circ} \mathrm{C} v s$ measured temperature $30.1 \pm 1.5^{\circ} \mathrm{C}$ ). Simulations showed that heat loss through the surgical wound was approximately 4.3 watts (W), which is about $6 \%$ of the total heat loss during orthopedic surgery. A heat balance for one patient during surgery is visualized in Figure 1. It was seen from simulations that the average evaporative heat loss was $9.8 \mathrm{~W}$, the convective heat loss was $0.5 \mathrm{~W}$, and the radiative heat gain (due to surgery light) was $6.0 \mathrm{~W}$. The calculated evaporative water loss was $15.7 \mathrm{~g} \cdot \mathrm{h}^{-1}$ on average. Although the surgical interventions described in this paper are not fully comparable with the experiments performed by Lamke $^{3}$ (back surgery $v s$ abdominal surgery), the evaporative heat losses observed in this study are in the same range as Lamke's values (range 2.1-32.2 $\mathrm{g} \cdot \mathrm{h}^{-1}$ ).

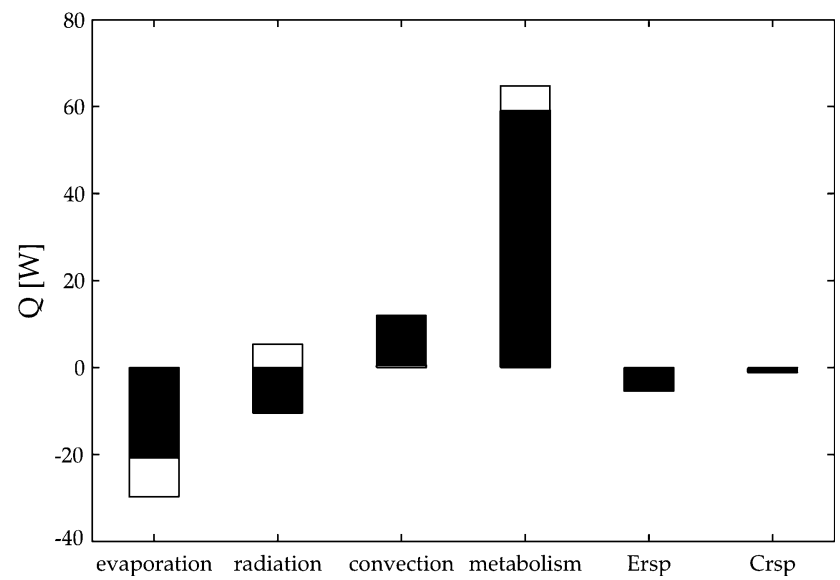

Fig. 1 Heat balance of a patient following the simulation. White parts represent the heat fluxes through the open back segment. Black parts represent the heat flows through the other body parts. Visible from left to right: evaporative heat loss $\left(Q_{e}\right)$, radiative heat loss $\left(Q_{r}\right)$, convective heat loss $\left(Q_{c}\right)$, metabolic heat production $(M)$, evaporative respiratory heat loss $\left(E_{r s p}\right)$ and dry respiratory heat loss $\left(C_{r s p}\right)$. The radiative heat gain of the open back segment is caused by the radiative heat flux of the surgery light. The convective heat gain comes from heat input of the forced-air heating blanket. In this specific case, the overall heat balance is positive, which means that the body is warming

Despite there being a limited number of cases studied, the model seems capable of predicting patient temperatures and surgical wound heat loss during (orthopedic back) surgery.

Competing interests None declared.

Open Access This article is distributed under the terms of the Creative Commons Attribution Noncommercial License which permits any noncommercial use, distribution, and reproduction in any medium, provided the original author(s) and source are credited.

\section{References}

1. Roe CF. Effect of bowel exposure on body temperature during surgical operations. Am J Surg 1971; 122: 13-5.

2. Sessler DI. Perioperative heat balance. Anesthesiology 2000; 92: 578-96.

3. Lamke LO, Nilsson G, Reithner HL. Water loss by evaporation from the abdominal cavity during surgery. Acta Chir Scand 1977; 143: 279-84.

4. Severens NM, van Marken Lichtenbelt WD, Frijns AJ, Van Steenhoven AA, de Mol BA, Sessler DI. A model to predict patient temperature during cardiac surgery. Phys Med Biol 2007; 52: $5131-45$. 